\title{
Research on the Macro-Model of the Microbolometer by Equivalent Circuit Method
}

\author{
X. Hu, C. Chen, Y.D Jiang, Y. Zhao \\ State key Laboratory of Electronic Thin films and Integrated Devices \\ University of Electronic Science and Technology of China \\ China
}

\begin{abstract}
Finite element analyzes is studied based on a three-dimensional model of microbolometer to extracting effective thermal conductivity, thermal capacity and initial resistance of the model. An equivalent electrocircuit of microbolometer is established, which present a macro-model of a microbolometer model by definition of key parameter mentioned above in Verilog-A hardware language under the simulation environment of integrated circuit. By using this method, the macro model of a microbolometer which can be used in circuit simulator to achieve coordinated simulation between designing of microbolometer and readout integrated circuit.
\end{abstract}

Keywords-microbolometer; macro-model; system level simulation; FEA

\section{INTRODUCTION}

Microbolometers are the typical monolithic integrated micro electro mechanical system (MEMS) and are popular in many commercial applications because of room temperature operation capability, compactness, ruggedness and less weight as compared to the high performance cooled semiconductor photon detectors [1-4]. The operating principle of microbolometers is detection temperature changing by device heat sensitive layer which caused by the changing of the thermal radiation [5-6].

As a monolithic integrated device, it is manufactured by COMS-MEMS, and simulation of this monolithic integrated device was studied in two methods. Structure design of microbolometer was accomplished by MEMS software and read out integrated circuit was designed by Cadence .etc. With the development of MEMS CAD technology, the design pattern of microbolometer was shifted from device lever design, towards system level design [7-8].

In this paper, we present a method to achieve system level simulation based on FEA simulation; extracting of macro-model of a microbolometer. Achievement of system level simulation can reduce the complex rate of design flow, shorten the development cycle, lessen development cost, and enhance the efficiency and quality of the design.

\section{THE MICROBOLOMETER MODEL DEVELOPMENT}

\section{A. The Key Parameters of Model}

The $\mathrm{G}$ presents how well the heat exchange between the bolometer element and the substrate through the support legs. $\mathrm{G}_{\text {eff }}$ is effective thermal conductance under loading bias current, which is proportional to loading bias current, and effective thermal conductance $\mathrm{G}_{\text {eff }}$ can be written as eqn (1).

$$
G_{e f f}=\frac{C}{\tau}
$$

Where $\tau$ is the thermal time constant, $\mathrm{C}$ is the total heat capacity, which signifies the amount of the material that needs to be heated up by the power supplied to the element either via biasing or radiations. It is expressed as eqn (2) [9-11].

$$
C=\Sigma V_{i} \cdot \rho_{i} \cdot c_{i}
$$

Where $V_{i}$ is the volume of each of the bolometer membrane, $\rho_{i}$ is the density of each materials and $c_{i}$ is the mass specific heat of each materials.

NETD is defined as the minimum change in temperature in the target scene and it can be given by eqn (3)

$$
N E T D=5 \cdot V_{n} \cdot \sqrt{G_{e f f}^{2}+w^{2} C^{2}} \cdot R_{0} \cdot C_{\text {int }} / \tau_{0} \cdot A_{d} \cdot \alpha \cdot \eta \cdot V_{\text {fid }} \cdot T_{\text {int }} \cdot(\partial P / \partial T)_{\Delta \lambda}
$$

Where $\mathrm{V}_{\mathrm{n}}$ is total noise; $\tau_{0}$ is the transmission of the optics in front of the pixel; $A_{d}$ is the area of detector pixel; $C_{i n t}$ is integrating capacitor; $\mathrm{T}_{\text {int }}$ is integral time; $\mathrm{C}$ is thermal capacity; $\mathrm{G}_{\text {eff }}$ is thermal conductance; $\eta$ is the infrared absorption rate; $V_{\text {fid }}$ is the bias voltage; $R_{0}$ is the device resistance; $\omega$ is the modulation rate.

$\mathrm{R}_{0}, \mathrm{G}_{\text {eff }}$ and $\mathrm{C}$ are three key parameters of microbolometer which have significant impact on the performance of device.

\section{B. The Model Development and Analysis}

A complete three-dimensional model of a microbolometer is built in MEMS simulation software Intellisuit which shown in fig. 1(a). Firstly, electronic performance is simulated. Current density $1.575 \times 10^{-8} \mathrm{~A} / \mathrm{um}^{2}$ is loaded on one of electrodes, and a $0 \mathrm{~V}$ voltage was load on the other electrode, and then electrical potential difference is obtained shown in fig. 1(b). Through volt-ampere laws, resistance value $\mathrm{R}_{0}$ can be calculated. The secondly step, initial temperature was defined as $27^{\circ} \mathrm{C}$. To ensure device temperature stabilized, a $30 \mathrm{~ms}$ thermal radiation impulse is delay for $40 \mathrm{~ms}$ compared to the bias current which shown in fig. 1(c) on thermal sensitive layer vanadium oxide. Then heat response time $\tau$ can be obtained from fig. 1(d). Through calculation, the thermal capacity $\mathrm{C}$ also can be obtained. The effective thermal 
conductance, $\mathrm{G}_{\text {eff }}$ and the thermal capacitance, $\mathrm{C}$ having relation given by eqn (1). $\mathrm{C}$ and $\tau$ are known, so effective thermal conductance is obtained.

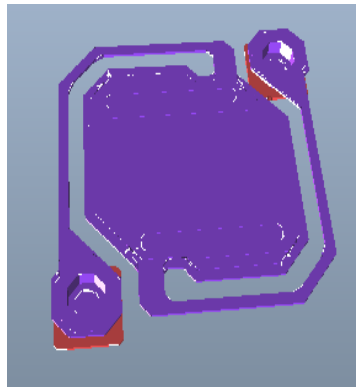

(a)

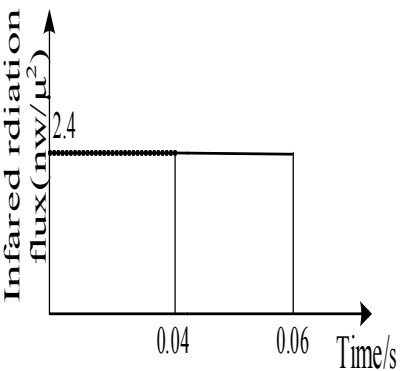

(c)

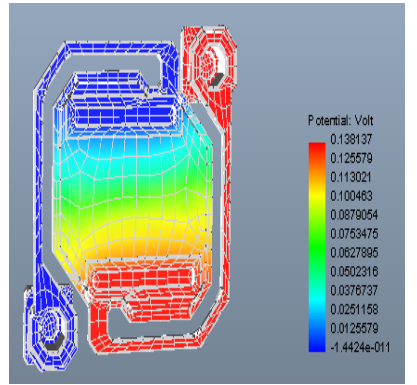

(b)

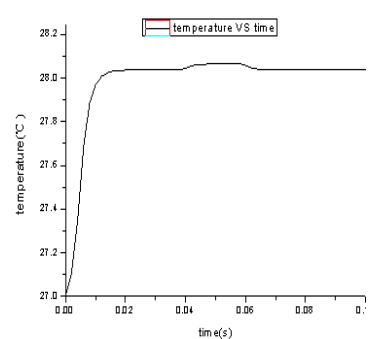

(d)
FIGURE I. (a): THREE-DIMENSIONAL MODEL OF A MICROBOLOMETER, (b): ELECTRICAL POTENTIAL DIFFERENCE ON SIMULATED PERFORMANCE OF A MICROBOLOMETER,(c): THERMAL RADIATION ENERGY VERSUS TIME CURVE, (d): TEMPERATURE VERSUS TIME CURVE

\section{MACRO-MODEL}

There is an inter-dependence of the electrical and the thermal behaviors of a microbolometer element. The bias heating changes the element's resistance, as well as the electrical power dissipated in the element increases its temperature which results in a recursive feedback process where electrical properties affect the thermal behavior and thermal properties affect the electrical behavior [12].

An equivalent circuit shown in fig. 2 expresses both the thermal and electrical behaviors of a microbolometer. An electrical analogous circuit of thermal behavior is necessary to represent the thermal performance of microbolometer and its implementation with proper conversion factors between thermal and electrical domains.

They have some equivalent as following:

Charge $\mathrm{q}(\mathrm{C}) \Leftrightarrow$ Thermal Energy $\mathrm{E}(\mathrm{J})$

Current $I=\frac{d q}{d t}(A) \Leftrightarrow$ Thermal Power $P=\frac{d E}{d t}(W)$

Potential V(V) $\Leftrightarrow$ Temperature $\mathrm{T}(\mathrm{K})$

Capacitance $C=I \frac{d t}{d V} \Leftrightarrow$ Heat Capacity $C_{t h}=\frac{d Q}{d T}$

Conductivity $\mathrm{G}\left(\mathrm{A} . \mathrm{V}^{-1}\right) \Leftrightarrow$ Thermal Conductance $\mathrm{G}_{\mathrm{th}}\left(\mathrm{W} \cdot \mathrm{K}^{-1}\right)$

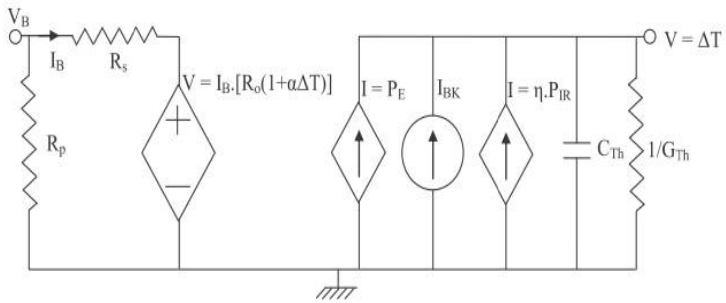

FIGURE II. AN EQUIVALENT CIRCUIT OF A MICROBOLOMETER

\section{PACKAGING}

The equivalent circuit shown in fig. 2 is described into six symbols by language Verilog-A. And then such symbols are defined a constant voltage circuit model of a microbolometer in Cadence which shown in fig. 3.

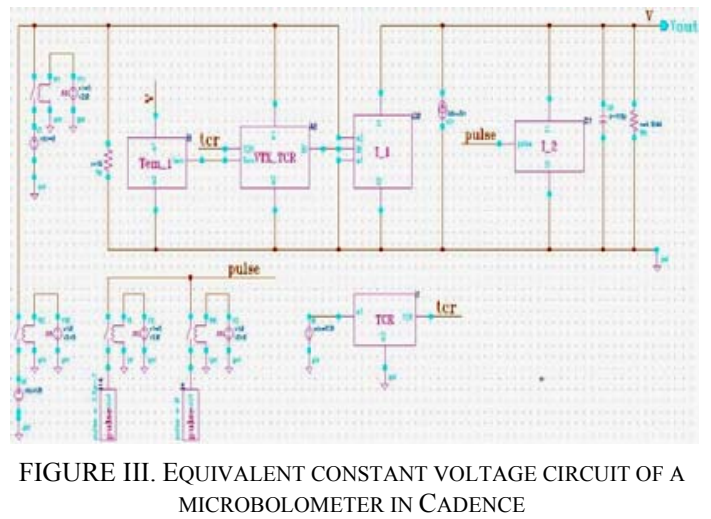

The packaging of description of equivalent circuit in Cadence is of great significance as it translates macro-model to some information which circuit simulation can recognize, and then it can achieve the real system level simulation.

\section{VERIFICATION}

The $\mathrm{C}$ signifies the amount of the material that needs to be heated up by the power supplied to the element either via biasing or radiations. Therefore, increased value of $\mathrm{C}$ will cause decrease in $\mathrm{T}$ of the bolometer element for the heat supplied to it in a given time, resulting in less responsivity, and less change in resistance. We set $1.25 \mathrm{~V}$ biasing voltage, and the $\mathrm{C}$ value is $4.19 \times 10^{-10} \mathrm{~J} / \mathrm{K}$ in Cadence and the signal is displayed in fig. 4 .

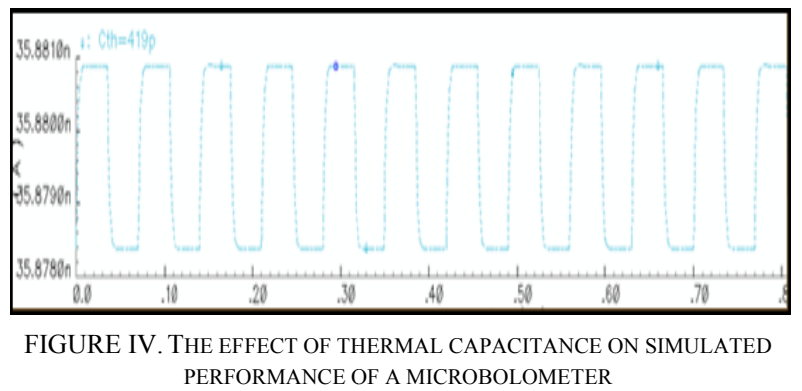

The $G_{\text {eff }}$ presents how well the heat exchange between the bolometer element and the substrate through the support legs. Increasing of $\mathrm{G}_{\text {eff }}$ will lead the decrease in the temperature rise 
of the element due to easier heat transfer towards the substrate. We set $1.25 \mathrm{~V}$ biasing voltage, and the $\mathrm{G}_{\text {eff }}$ value is $2.39 \times 10^{-7} \mathrm{~J} / \mathrm{K}$ in Cadence and the output signal is displayed in fig. 5 .

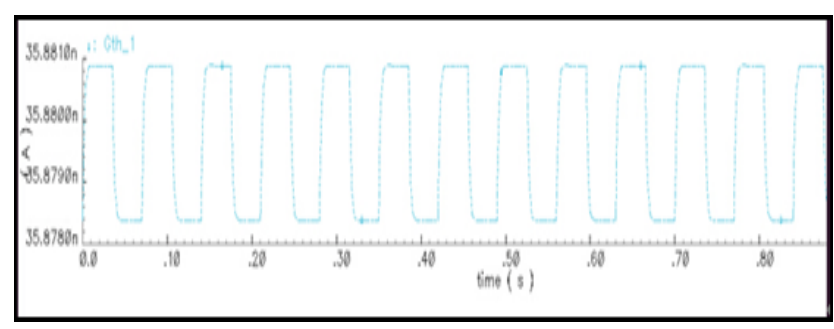

FIGURE V. THE EFFECT OF THERMAL CONDUCTANCE ON SIMULATED PERFORMANCE OF A MICROBOLOMETER

The TCR signifies the relationship between resistance and temperature. In our model, the TCR value of thermal sensitive material vanadium oxide is -0.02 . We set voltage range from $340 \mathrm{mV} \sim 1.25 \mathrm{~V}$, and the optical input was given in pulse form with $70 \mathrm{~ms}$ period and $50 \%$ duty cycle. The signal is displayed in fig. 6(a). In the same situation of optical input, the biasing voltage is set $1.25 \mathrm{~V}$, and the signal in Cadence is displayed in fig. 6(b).
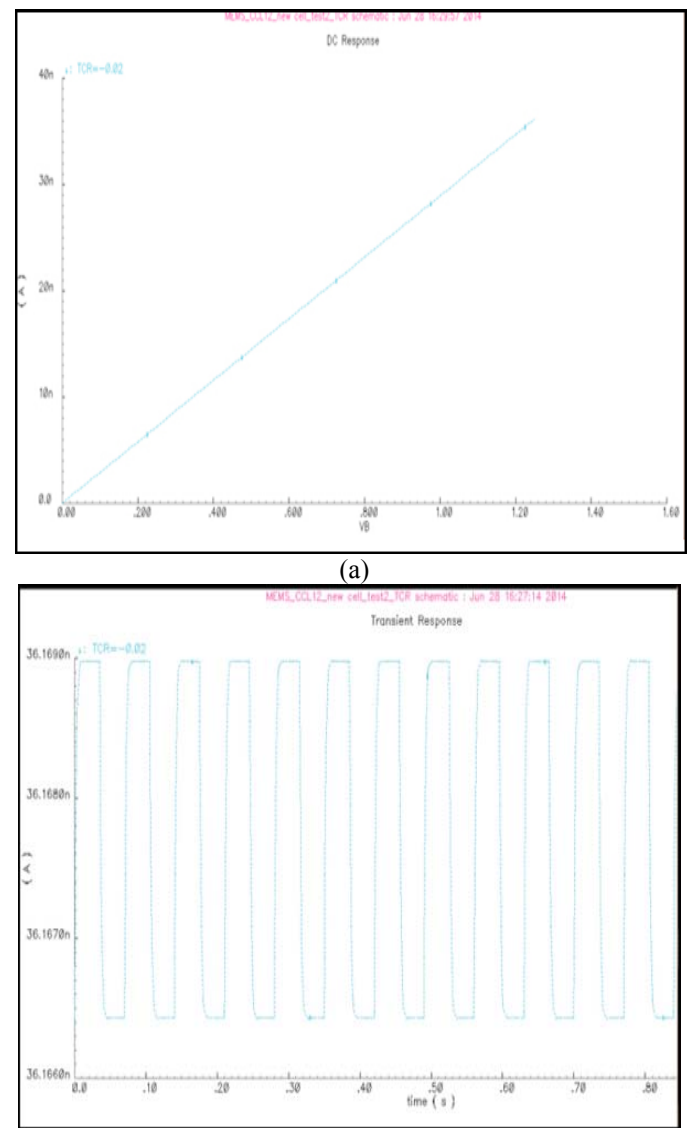

(b)

FIGURE VI. THE EFFECT OF TCR ON: (a) DC I-V CHARACTERISTICS, (b) THE RESPONSE OF THE MICROBOLOMETER TO CHOPPED IR RADIATIONS

\section{CONCLUSIONS}

Finite element analysis was studied based on a three-dimensional model of microbolometer to extracting effective thermal conductivity, thermal capacity and initial resistance of the model. The equivalent circuit of a microbolometer which obtains the parameters mentioned above are defined and packed in circuit. Finally, coordinated simulation between designing of a microbolometer and readout integrated circuit is accomplished which provide a possibility to a system level simulation of a microbolometer and readout integrated circuit.

\section{REFERENCES}

[1] Bhan, R.K., Saxena, R.S., Jalwania, C.R. \& Lomash, S.K., Uncooled infrared microbolometer arrays and their characterisation techniques. Defence Science Journal, 59, pp. 580-589, 2009.

[2] Tissot, J.L., IR detection with uncooled focal plane arrays, State-of-the art and trends, Opto-Electronics Review, 12(1), pp. 105-109, 2004.

[3] Capper, P. C. \& Elliott, T., Infrared Detectors and Emitters: Materials and Devices, Kluwer Academic Publishers: USA, 2001.

[4] Wood, R.A., Kruse, P.W. \& Skatrud D.D., (eds.). Uncooled Infrared Imafing Arrays and Systems, Academic Press: San Diego, pp.45-119, 1997.

[5] Sun G. C., Ha T. J. \& Hyung, H. P., Effective heat conservation in a sandwich-structured micro bolometer using mesoporous TiO2. Sensors and Actuators, A 155, pp. 131-135, 2009.

[6] Wang, H. C., Huang, G. \& Yi, X. J., IR micro bolometer with self-supporting structure operating at room temperature, Infrared Physics \& Technology, 45, pp. 53-57, 2004.

[7] Raghvendra S. S. \& Arun P., A sub-circuit model of a microbolometer IR detector and its experimental validation. Sensors and Actuators, A 171, pp. 138-145, 2011.

[8] Sedra, A. S. \& Smith, K.C., Microelectronic Circuits, Oxford University Press: USA, 2003.

[9] Frank N., Adit D. \& Christer J., Performance model for uncooled infrared bolometer arrays and performance predictions of bolometer operating at atmospheric pressure. Infrared physic \& Technology, 51, pp. 168-177, 2008.

[10] Lin, X. D., Liang, P. Z. \& Shen, X. C., Analysis of bias heating effect in uncooled infrared microbolometer and determination of its main parameters. Infrared millimeter waves, 18(1), 1999.

[11] Eriksson, P., Andersson, J.Y \& Stemme, G., Thermal characterization of surface-micro machined silicon nitride membranes for thermal infrared detectors. IEEE Journa lof Micro electromechanical Systems, 6 (1), pp. 55-61, 1997.

[12] Saxena, R. S. \& Panwar, A., A sub-circuit model of a microbolometer IR detector and its experimental validation. Sensors and Actuators, A171, pp. 138-145, 2011. 